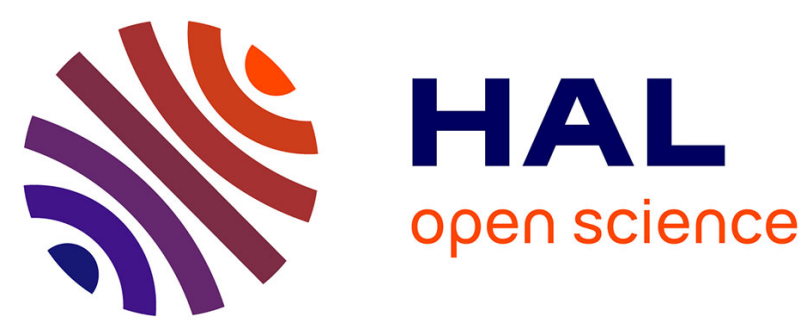

\title{
Automatic optimization of the cooling of injection mold based on the boundary element method
}

\author{
E Mathey, Luc Penazzi, Fabrice Schmidt, F Ronde-Oustau
}

\section{To cite this version:}

E Mathey, Luc Penazzi, Fabrice Schmidt, F Ronde-Oustau. Automatic optimization of the cooling of injection mold based on the boundary element method. NUMIFORM 2004 - 8th International conference on numerical methods in industrial forming processes, Jun 2004, Columbus, United States. pp.222-227. hal-01716287

\section{HAL Id: hal-01716287 \\ https://hal.science/hal-01716287}

Submitted on 5 Mar 2019

HAL is a multi-disciplinary open access archive for the deposit and dissemination of scientific research documents, whether they are published or not. The documents may come from teaching and research institutions in France or abroad, or from public or private research centers.
L'archive ouverte pluridisciplinaire HAL, est destinée au dépôt et à la diffusion de documents scientifiques de niveau recherche, publiés ou non, émanant des établissements d'enseignement et de recherche français ou étrangers, des laboratoires publics ou privés. 


\title{
Automatic optimization of the cooling of injection mold based on the boundary element method
}

\author{
E. Mathey*, L. Penazzi*, F.M. Schmidt* and F. Rondé-Oustau* \\ ${ }^{*}$ Research Center on Tools, Materials and Forming Processes, Ecole des Mines d'Albi, \\ Campus Jarlard, Route de Teillet, 81013 ALBI Cedex 09, FRANCE
}

\begin{abstract}
Part cooling during injection molding is the critical step as it is the most time consuming. An inefficient mold cooling may have dramatic consequences on cycle time and part quality and may require expensive mold rectification. In order to reduce mold and production costs, an automatic optimization of cooling device geometry and processing parameters (temperature, flow rate...) has been developed. The first step of the optimization is to choose parameters describing the geometry of the cooling device (which may be complex in case of molds obtained by prototyping process). Then numerical simulation of the heat transfer during cooling stage is coupled to a non linear constraint optimization method (sequential quadratic programming). The objective is to find the best set of parameters according to a cost function representing cooling uniformity and/or cooling speed. At each step of the optimization, the boundary element method is used to solve the heat transfer equation (the dual reciprocity method is used for transient problems) and to determine the effect of the parameters on the cost function. The main advantage of the BEM is that remeshing procedure is easier. As a validation, the method is applied to $2 \mathrm{D}$ mold geometries representative of difficulties arising during cooling of real industrial parts (with thickness changes or angles). The first computations show fair results.
\end{abstract}

\section{INTRODUCTION}

Rapid prototyping processes such as laminated object manufacturing (stratoconception) or selective laser sintering start to be used to make production injection molds. Beside possible cost and delay reductions, the advantage of these building processes is the possibility to get almost any shape of mold geometry. An interesting application of this feature could be the improvement of the cooling of injection molds (by using conformal and complex cooling channels) $[1,2]$.

\section{Simulation of heat transfer during injection molding}

Several CAD and simulation tools are available to help designing the cooling system of an injection mold. Simulation of heat transfer during injection can be used to check a mold design or study the effect of a parameter (geometry, materials...) on the cooling performance of the mold. Several numerical methods such as Finite Elements Method (FEM) [3] or Boundary Element Method (BEM) [4] can be used. Bikas [5] used C-Mold® simulations and design of experiments to fi nd expressions of mean temperature and temperature variation as functions of geometry parameters of the mold.

\section{Mold cooling optimization approaches}

Numerical simulation can also be used to perform an automatic optimization of the mold cooling. Numerical simulation is used to solve the thermal equations and evaluate a cost function related to productivity or part quality. An optimization method is used to modify the parameters and improve the thermal performance of the mold.

Tang $[6,7]$ used 2D transient FEM simulations coupled with Powell's optimization method [8] to optimize the cooling channel geometry to get uniform temperature in the polymer part. Huang [9] used 2D transient FEM simulations to optimize the use of molds materials according to part temperature uniformity or cycle time.

Park [10, 11, 12] developped 2D and 3D stationary BEM simulations in the injection molds coupled with 1D transient analytical computation in the polymer part (throughout the thickness). The heat transfer integral equation is differentiated to get sensitivities of a cost function to the parameters [11]. The calculated sensitivities are then used to optimize the position of linear cooling channels for simple shapes (sheet, box) [12].

In this paper, an optimization procedure is developed to improve cooling of injection molds. The model uses a mathematical programming method (Sequential Quadratic Programming [13]) to modify and improve automatically the geometry and the process parameters ac- 


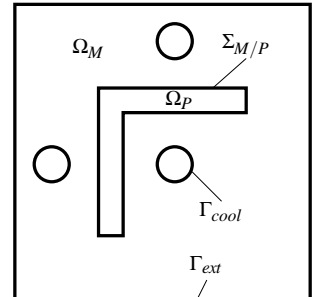

FIGURE 1. Domain and boundary definition

cording to an objective function (e.g. cooling time or temperature uniformity). The SQP method is coupled with the boundary element method to solve thermal problems of cooling during injection (both stationary and transient). The method is used on 2D geometries but with complex cooling channel geometries which could be obtained by rapid tooling processes.

\section{HEAT BALANCE EQUATION}

Two types of heat transfer problems representing cooling during injection molding are solved :

- a transient problem allowing to get evolutions of temperature both in the mold and the polymer during the cooling step of the injection cycle;

- a easier-to-solve stationary problem to get the mean temperature in the mold during a stabilized cycle.

Equations corresponding to these problems are detailled in the following paragraphs.

\section{Transient heat transfer}

At time $t=0$, the mold $\left(\Omega_{M}\right)$ and the polymer part $\left(\Omega_{P}\right)$ are put into contact (fi gure 1). The mold is initially at a uniform temperature equal to coolant temperature $\left(T_{C}\right)$ and the polymer is at injection temperature $\left(T_{\text {injection }}\right)$. The evolutions of temprature in the mold and in the polymer are governed by equation (1).

$$
\begin{cases}\forall M \in \Omega_{M}, & \vec{\nabla}^{2} T_{M}=\frac{\rho_{M} C_{M}}{\lambda_{M}} \frac{\partial T_{M}}{\partial t}=\frac{1}{a_{M}} \frac{\partial T_{M}}{\partial t} \\ \forall M \in \Omega_{P}, & \vec{\nabla} T_{P}=\frac{\rho_{P} C_{P}}{\lambda_{P}} \frac{\partial T_{P}}{\partial t}=\frac{1}{a_{P}} \frac{\partial T_{P}}{\partial t}\end{cases}
$$

The mold/polymer contact is modeled using a thermal contact resistance $R$ and is taken into account on the interface $\Sigma_{M / P}$ using following relations :

$$
\forall M \in \Sigma_{M / P}, \quad\left\{\begin{array}{l}
\lambda_{M} \vec{\nabla} T_{M}=\lambda_{P} \vec{\nabla} T_{P} \\
R \lambda_{M} \vec{\nabla} T_{M}=\left(T_{M}-T_{P}\right)
\end{array}\right.
$$

The external boundary of the mold insert (in contact with the holding block of the mold or ambient air) is assumed adiabatic [6]

$$
\forall M \in \Gamma_{e x t}, \quad \vec{\nabla} T_{M} \cdot \vec{n}=0
$$

The cooling channel surface is subject to convection from the coolant which is at a temperature $T_{C}(4)$. The heat transfer coeffi cient $h$ is related to coolant flow rate (via Nusselt number $\mathrm{Nu}$ ), coolant properties and channel geometry.

$$
\forall M \in \Gamma_{\text {cool }},-\lambda_{M} \vec{\nabla} T_{M}=h\left(T_{M}-T_{C}\right)=\frac{N u \lambda_{C}}{D}\left(T_{M}-T_{C}\right)
$$

\section{Stationary heat transfer}

In the particular case of stationary heat transfer, equation (5) can be solved in the mold only to get a mean repartition of temperature during cooling.

$$
\forall M \in \Omega_{M}, \quad \vec{\nabla}\left(\lambda_{M} \vec{\nabla} T_{M}\right)=0
$$

The polymer is then taken into account with a heat flux on the mold cavity surface. The flux density is calculated from the cycle time and polymer properties (heat due to polymer crystallization is neglected).

$$
\forall M \in \Sigma_{M / P}, \quad-\lambda_{M} \vec{\nabla} T_{M} \cdot \vec{n}=\frac{\rho_{P} V_{P} C_{P}\left(T_{\text {inject }}-T_{\text {eject }}\right)}{S t_{\text {cooling }}}
$$

Boundary conditions on $\Gamma_{e x t}$ and $\Gamma_{\text {cool }}$ are unchanged.

\section{HEAT TRANSFER SIMULATION USING BOUNDARY ELEMENT METHOD}

The Boundary Element Method (BEM) is used to solve previous equations. Details on the method used can be found in [14] and in [15]. This method has been developed to make re-meshing for each optimization iteration easier as only $1 \mathrm{D}$ meshing is needed to solve 2D problems.

\section{Stationary heat transfer}

The BEM [14] is used to solve stationary heat transfer problems described by equation (5) with a constant conductivity $\lambda$.

Multiplying equation (5) by weighting function $T^{*}$, integrating over the domain and using integration by parts and Green's theorem twice leads to equation (7), where 


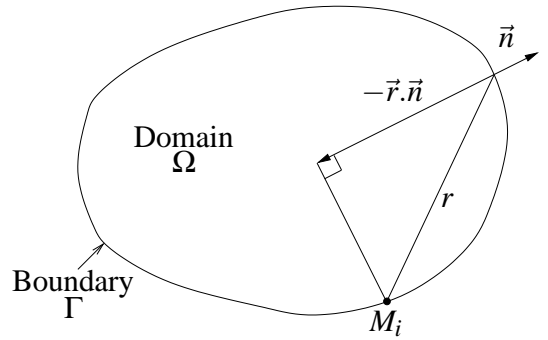

FIGURE 2. Definition of distances used to compute fundamental solutions

$T_{i}$ is the temperature at point $M_{i}, q$ is he temperature gradient and $c$ is equal to $\frac{1}{2}$ on a regular boundary and 1 inside the domain.

$$
c T_{i}+\int_{\Gamma} T \cdot q^{*} d \Gamma=\int_{\Gamma} q \cdot T^{*} d \Gamma
$$

$T^{*}$ and $q^{*}$ are the fundamental solutions defi ned for 2D problems by equations (8) where $r$ is the distance between point $M_{i}$ and any boundary point (fi gure 2).

$$
\left\{\begin{array}{l}
T^{*}=\frac{1}{2 \pi} \ln \frac{1}{r} \\
q^{*}=\vec{\nabla} T^{*} \cdot \vec{n}=\frac{-\vec{r} \cdot \vec{n}}{2 \pi r^{2}}
\end{array}\right.
$$

The boundary $\Gamma$ of the domain is divided into $N_{e}$ elements. After discretization, equation (7) becomes :

$$
c T_{i}+\sum_{j=1}^{N e} \int_{\Gamma_{j}} T \cdot q^{*} d \Gamma=\sum_{j=1}^{N e} \int_{\Gamma_{j}} q \cdot T^{*} d \Gamma
$$

Applying equation (9) to all nodes on the boundary and writing $H_{i j}=c \delta_{i j}+\int_{\Gamma_{j}} q^{*} d \Gamma$ and $G_{i j}=\int_{\Gamma_{j}} T^{*} d \Gamma$ result in a system of linear equations can be written in matrix form :

$$
[H]\{T\}=[G]\{q\}
$$

After applying the boundary conditions ( $T$ or $q$ or a combination of both), the system of equations can be solved. Temperature at a point $M_{k}$ inside the domain can then be calculated using results on the boundary :

$$
\left\{T_{k}\right\}=[G]\{q\}-[H]\{T\}
$$

\section{Transient heat transfer}

The Dual Reciprocity Method (DRM) [15] associated with the BEM allows to solve transient heat transfer problems described by equation (1). The DRM consists in seeking the solution as series of particular solutions $\hat{T}$ and $\hat{q}$ interpolated on $N$ points inside and on the boundary of the domain.

$$
\vec{\nabla}^{2} T=\sum_{k=1}^{N} \alpha_{k} \vec{\nabla}^{2} \hat{T}_{k} \text { with }\left\{\alpha_{k}\right\}=\frac{1}{a}[F]^{-1}\left\{\dot{T}_{k}\right\}
$$

Matrix $[F]$ consists of values of interpolation function $f$ at each point. A commonly used interpolation function is the polynomial radial function (13) leading to particular solutions (14).

$$
\left\{\begin{array}{c}
f=1+r+r^{2}+r^{3} \\
\hat{T}=\frac{r^{2}}{4}+\frac{r^{3}}{9}+\frac{r^{4}}{16}+\frac{r^{5}}{25} \\
\hat{q}=\left(r_{x} \frac{\partial x}{\partial n}+r_{y} \frac{\partial y}{\partial n}\right)\left(\frac{1}{2}+\frac{r}{3}+\frac{r^{2}}{4}+\frac{r^{3}}{5}\right)
\end{array}\right.
$$

Applying the BEM to the modifi ed equation (12) leads to the new linear system of equations (15).

$$
[H]\{T\}-[G]\{q\}=\frac{1}{a}([H][\hat{T}]-[G][\hat{Q}])[F]^{-1}\{\dot{T}\}
$$

A Newmark time scheme is applied to the temperature and flux leading to equation (16) where $[C]=$ $\frac{-1}{a}([H][\hat{T}]-[G][\hat{Q}])[F]^{-1}$.

$$
\begin{aligned}
& \left(\theta_{T}[H]+\frac{1}{\delta t}[C]\right)\left\{T^{n+1}\right\}-\theta_{q}[G]\left\{q^{n+1}\right\}= \\
& -\left(\left(1-\theta_{T}\right)[H]-\frac{1}{\delta t}[C]\right)\left\{T^{n}\right\}+\left(1-\theta_{q}\right)[G]\left\{q^{n}\right\}
\end{aligned}
$$

Multi-domain computation for contact simulation (mold polymer contact) is performed by introducing continuity equation [16] before boundary conditions and solving the system at each time step.

\section{MOLD COOLING OPTIMIZATION}

Heat transfer computation is coupled with an optimization method to automatically modify parameters at each optimization iteration as shown in fi gure 3. Given initial parameters, the BEM simulation is performed and the cost function is calculated. The optimization method allows to update parameters according to constraints until a minimum of the cost function is found. Sequential Quadratic Programming [13] is used for the optimization of continuous non linear functions with continuous non linear constraints.

\section{Cost function}

The objective or cost function $F$ to minimize is a function of the parameters $X$ chosen according to the 


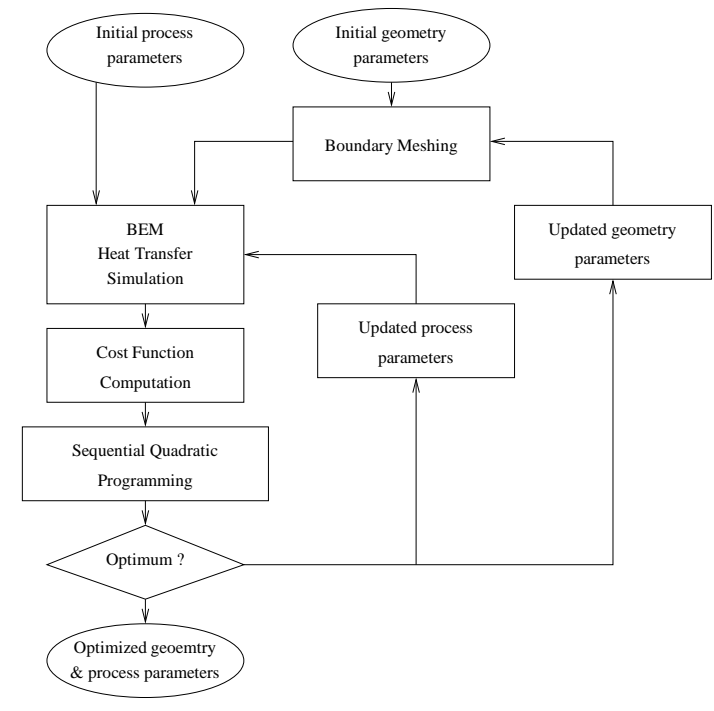

FIGURE 3. Heat transfer simulation / optimization coupling

results available from the simulation results (stationary or transient). The general form of the cost function can be written as functions of temperature $T$ and heat flux $\Phi$ inside domains or on the boundaries (17). Examples of cost functions are given in the next paragraph.

$F(X)=\int_{\Omega} F_{1}(T(X), \Phi(X)) d \Omega+\int_{\Gamma} F 2(T(X), \Phi(X)) d \Gamma$

\section{Parameters}

Both process and geometry parameters can be included in the optimization. Process parameters defi ne the thermal regulation : properties, temperature and flow of the coolant. Position and dimensions of the cooling channels are used to describe the cooling device geometry. In this study, circular and elliptical cooling channels (which could be obtained by a rapid tooling process) are considered, ie. respectively 3 and 5 parameters are needed to describe each cooling channel.

\section{Constraints}

Constraints on parameters are expressed as bounds (18) or as equalities/inequalities of relations between several parameters (19). Examples of constraints are given in the next paragraph.

$$
\begin{gathered}
X_{i}^{\min } \leq X_{i} \leq X_{i}^{\max } \\
g_{1}(X)<0 \text { or } g_{2}(X)=0
\end{gathered}
$$

\section{APPLICATION 1 : "T" SHAPED PART}

The method is also used to optimize the mold depicted on fi gure (4). The example was solved by Tang [6] with a transient FEM analysis. The stationary BEM is used to evaluate the objective function at the mold cavity surface. Properties of mold, polymer and coolant used for simulation are summarized in table 1 .

The objective function is related to temperature uniformity at the mold cavity surface compared to initial values

$$
\begin{gathered}
F(X)=0.5 F_{1}(X)+0.5 F_{2}(X) \\
\text { with } F_{1}(X)=\frac{\left[\int_{\Sigma}(\bar{T}(X)-T(X))^{2} d \Sigma\right]^{\frac{1}{2}}}{F_{1}^{0}(X)} \\
\text { and } F_{2}(X)=\frac{T_{\max }(X)-T_{\min }(X)}{F_{2}^{0}(X)}
\end{gathered}
$$

The parameters defi ning the geometry are shown in figure 4. Two types of constraints are considered [6] :

- geometric constraints to keep cooling channels in the mold and to avoid collisions;

- flow related constraints to force a turbulent flow.

Results obtained with the stationary BEM / SQP algorithm show differences from 10 to $20 \%$ with results obtained with the transient FEM / Powell's method (table 2 and fi gure 5). This difference can be explained by the fact that $F$ is evaluated using the mean temperature during one cycle with stationary BEM and at the end of cooling time with transient FEM. Anyway, results show a very good improvement of the cavity surface temperature as the maximum difference of temperature is decreased from $25^{\circ} \mathrm{C}$ to $7^{\circ} \mathrm{C}$ (fi gure 6).

TABLE 1. Thermal Properties of the mold, polymer and coolant materials

\begin{tabular}{cccc}
\hline & Mold & Polymer & Coolant \\
\hline$\lambda\left[\mathrm{W} \cdot \mathrm{m}^{-1} \cdot \mathrm{K}^{-1}\right]$ & 36.5 & 0.25 & 0.63 \\
\hline$\rho\left[\mathrm{kg} \cdot \mathrm{m}^{-3}\right]$ & 7820 & 996 & 996 \\
\hline$C\left[\mathrm{~J} \cdot \mathrm{kg}^{-1} \cdot \mathrm{K}^{-1}\right]$ & 460 & 1800 & 4180 \\
\hline
\end{tabular}

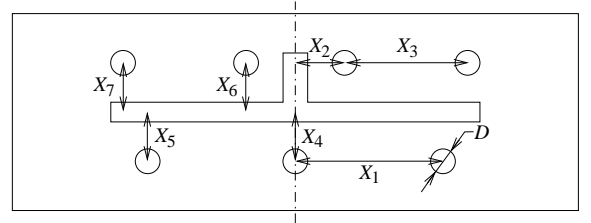

FIGURE 4. Definition of the geometry parameters 
TABLE 2. Values of optimized geometrical parameters compared to [6]

\begin{tabular}{cccc}
\hline $\begin{array}{c}\text { Parameters } \\
{[\mathrm{cm}]}\end{array}$ & $\begin{array}{c}\text { Initial } \\
\text { values }\end{array}$ & $\begin{array}{c}\text { Optimized } \\
\text { values }\end{array}$ & $\begin{array}{c}\text { Optimized } \\
\text { values [6] }\end{array}$ \\
\hline$D$ & 0.76 & 0.68 & 0.74 \\
\hline$X_{1}$ & 6.10 & 3.99 & 3.57 \\
\hline$X_{2}$ & 2.03 & 1.34 & 1.5 \\
\hline$X_{3}$ & 6.10 & 5.15 & 4.67 \\
\hline$X_{4}$ & 1.49 & 1.14 & 1.51 \\
\hline$X_{5}$ & 1.51 & 1.23 & 1.54 \\
\hline$X_{6}$ & 1.26 & 1.07 & 1.30 \\
\hline$X_{7}$ & 1.77 & 1.60 & 2.01 \\
\hline
\end{tabular}

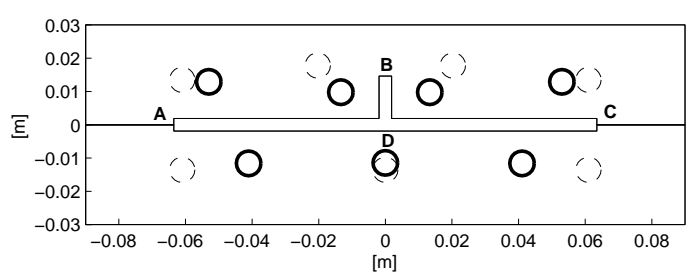

FIGURE 5. Initial (- -) and optimized (-) cooling channel positions and size

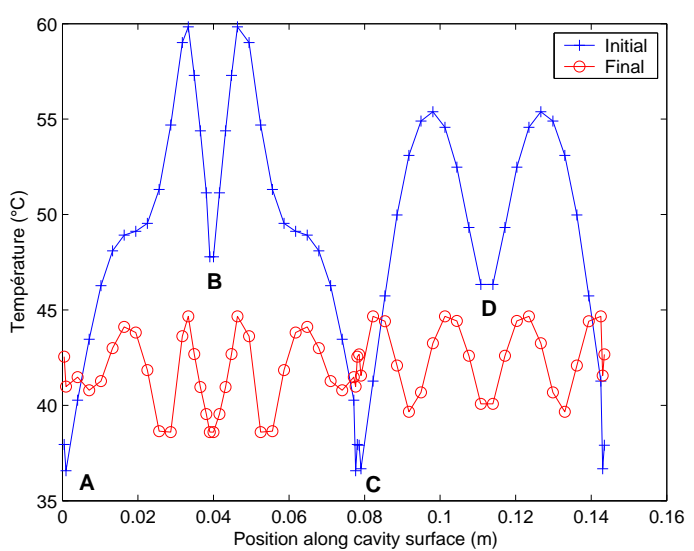

FIGURE 6. Comparison of temperature at the mold cavity surface

\section{APPLICATION 2 : ANGULAR PART COOLING}

The method developed is used to optimize the cooling of a mold producing angular parts. The effect of cooling channel shape is investigated in this example. The cooling device is composed of 3 circular or elliptical cooling channels, each constrained in one zone of the mold (fi gure 7). In case of circular cooling channels and using symmetry of the problem, the parameters used are :

- cooling channel positions $X_{1}, X_{2}, X_{3}$

- cooling channel size $X_{4}, X_{5}$

- coolant temperature $X_{6}$

Assuming that each cooling channel must stay in zones defined with dashed lines on fi gure 7 , the following constraints are assumed, where $\delta$ is a gap between the cooling channel and the mold surface :

$$
\left\{\begin{aligned}
X_{2}-X_{4}-\delta & >0 \\
X_{2}+X_{4}+\delta & <0.05 \\
X_{1}-X_{5} & >0.05+\delta+t \\
X_{2}+X_{3}+X_{4} & <0.15-\delta \\
X_{3}-X_{4} & >\delta
\end{aligned}\right.
$$

A minimum and maximum radiuses are needed for the cooling channel to allow manufacturing of the mold and turbulent flow :

$$
\left\{\begin{array}{l}
R_{\text {min }}<X_{4}<R_{\text {max }} \\
R_{\text {min }}<X_{5}<R_{\text {max }}
\end{array}\right.
$$

Finally, a range of temperature is imposed :

$$
T_{\min }<X_{6}<T_{\max }
$$

Equivalent parameters (center positions and two radius dimensions) and relations are used with elliptical cooling channels. Two parameters (second ellipse radius) are then added to the problem.

The objective function (24) is a combination of the cooling time $t_{\text {cooling }}$ and the difference of the part temperature to the average part temperature $\bar{T}$ compared to initial values.

$$
F(X)=0.5 \frac{t_{\text {cooling }}(X)}{t_{\text {cooling }}^{0}}+0.5 \frac{\int_{\Omega_{P}}(\bar{T}(X)-T(X)) d \Omega}{\left(\int_{\Omega_{P}}(\bar{T}-T) d \Omega\right)^{0}}
$$

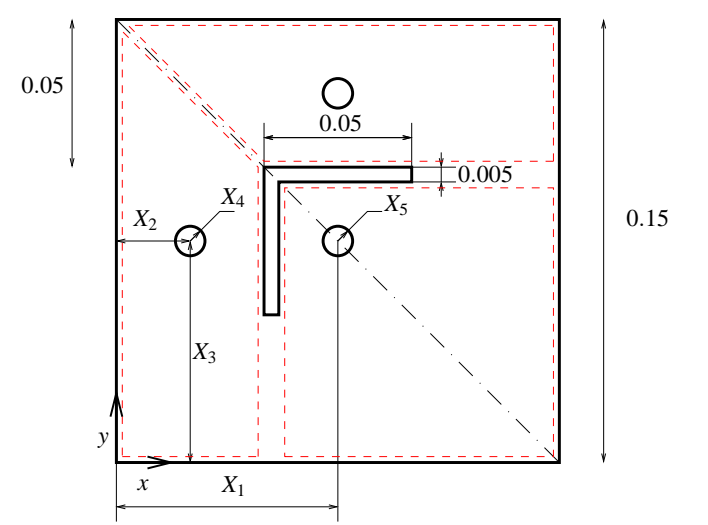

FIGURE 7. Mold geometry and parameters definition 
TABLE 3. Initial and final parameters for application case 2

\begin{tabular}{cccccccc}
\hline & $X_{1}[\mathrm{~cm}]$ & $X_{2}[\mathrm{~cm}]$ & $X_{3}[\mathrm{~cm}]$ & $X_{4}[\mathrm{~cm}]$ & $X_{5}[\mathrm{~cm}]$ & $X_{6}\left[{ }^{\circ} \mathbf{C}\right]$ & $F(X)$ \\
\hline Initial & 7.5 & 2.5 & 7.5 & 0.5 & 0.5 & 40 & 1 \\
\hline $\begin{array}{c}\text { Final } \\
\text { (circular channel) }\end{array}$ & 7.17 & 3.34 & 7.54 & 0.388 & 0.677 & 20 & 0.98 \\
\hline $\begin{array}{c}\text { Final } \\
\text { (elliptical channel) }\end{array}$ & 6.99 & 3.10 & 7.32 & $0.37 \times 0.84$ & $1.00 \times 0.49$ & 20 & 0.95 \\
\hline
\end{tabular}

The transient heat equation is solved with the DRM using properties summarized in table 1 . The heat transfer coeffi cient is updated to take into account cooling channel size and shape change according to equation (4).

Final geometry parameters obtained with elliptical and circular channels are shown in table 3. Cooling time reduction is very low as the part is $5 \mathrm{~mm}$ thick but a small improvement in temperature uniformity in the part is obtained. The optimized confi guration obtained with elliptical channels is slightly better than with circular channels.

\section{CONCLUSION}

The BEM has be used to solve the heat transfer equation during the cooling step of the injection molding process. Results of the simulation are used in an optimization procedure to fi nd the best geometry and process parameters according to a cost function. Results obtained with the presented method are close to those obtained by other methods found in the literature. The use of elliptical cooling channels showed a small advantage here and should be further investigated for more complex shapes.

\section{SYMBOL LIST}

$M, P$ and $C$ indices refer respectively to the mold, the polymer part and the coolant.

$\begin{array}{ll}a & \text { diffusivity }\left[\mathrm{m}^{2} \cdot \mathrm{s}-1\right] \\ C & \text { specifi c heat }\left[\mathrm{J} \cdot \mathrm{kg}^{-1} \cdot \mathrm{K}^{-1}\right] \\ D & \text { cooling channel diameter }[\mathrm{m}] \\ h & \text { convective heat transfer coeffi cient }\left[W \cdot \mathrm{m}^{2} \cdot K^{-1}\right. \\ S & \text { surface }\left[\mathrm{m}^{2}\right] \\ q & \text { temperature gradient } \vec{\nabla} T \cdot \vec{n}\left[K \cdot \mathrm{m}^{-1}\right] \\ R & \text { thermal contact resistance }\left[K \cdot \mathrm{m}^{2} \cdot \mathrm{W}^{-1}\right] \\ t_{\text {cooling }} & \text { estimated cooling time }[s] \\ T & \text { temperature }\left[{ }^{\circ} \mathrm{C}\right] \\ V & \text { volume }\left[\mathrm{m}^{3}\right] \\ \lambda & \text { conductivity }\left[\mathrm{W} \cdot \mathrm{m}^{-1} \cdot \mathrm{K}^{-1}\right] \\ \Phi & \text { heat flux }\left[\mathrm{W} \cdot \mathrm{m}^{-2}\right] \\ \rho & \text { density }\left[\mathrm{kg} \cdot \mathrm{m}^{-3}\right]\end{array}$

\section{REFERENCES}

1. Hopkinson, N., and Dickens, P., "Conformal cooling and heating channels using sintered tools," in Solid Freeform Proceedings, 2000, pp. 490-496.

2. Dalgarno, K., and Stewart, T., Proccedings of the Institution of Mechanical Engineers, Part B, Journal of Engineering Manufacture, 215, 1323-1332 (2001).

3. Boillat, E., Glardon, R., and Paraschivescu, D., Journal de Physique IV, 102, 27-38 (2002).

4. Hu, S., Cheng, N., and Chen, S., Plastics, Rubber and Composites Processing and Applications, 23, 221-232 (1995).

5. Bikas, A., and Kanarachos, A., "The dependence of cooling channels system geometry parameters on product quality as a result of uniform mold cooling," in Proceedings of the 57th Annual Technical Conference ANTEC 99, 1999, pp. 578-583.

6. Tang, L., Pochiraju, K., Chassapis, C., and Manoochehri, S., Journal of Mechanical Design, 120, 165-174 (1998).

7. Tang, L., Chassapis, C., and Manoochehri, S., Finite Elements Analysis and Design, 26, 229-251 (1997).

8. Fletcher, R., Practical methods of optimization, Wiley, 1987.

9. Huang, J., and Fadel, G., Journal of Mechanical Design, Vol. 123, 226-239 (2001).

10. Park, S., and Kwon, T., Journal of Manufacturing Science and Engineering, 120, 287-295 (1998).

11. Park, S., and Kwon, T., Journal of Manufacturing Science and Engineering, 120, 296-305 (1998).

12. Park, S., and Kwon, T., Polymer Engineering and Science, 38, 1450-1462 (1998).

13. Optimization Toolbox For Use With Matlab®, The MathWorks (2002), User's Guide, Version 2.

14. Brebbia, C., and Dominguez, J., Boundary elements, an introductory course, WIT Press/Computational Mechanics Publications, 1992.

15. Partridge, P., Brebbia, C., and Wrobel, L., The Dual Reciprocity Boundary Elemenet Method, Computational Mechanics Publications, 1992.

16. Florez, W., Multidomain dual reciprocity method for the solution of nonlinear flow problems, Ph.D. thesis, University of Wales (2000). 